\title{
METODE PENYISIHAN PIUTANG TAK TERTAGIH PADA PRODUK QARDH DI BANK PEMBIAYAAN RAKYAT SYARIAH BAROKAH DANA SEJAHTERA YOGYAKARTA PERIODE 2017
}

\author{
Januar Daningrum', Mikhriani² \\ ${ }^{1}$ Manajemen Dakwah, UIN Sunan Kalijaga Yogyakarta \\ danning_d@yahoo.co.id \\ ${ }^{2}$ Dosen UIN Sunan Kalijaga Yogyakarta \\ mikhriani@aol.com
}

\begin{abstract}
The giving of credit is one of the products that become a mainstay for the bank. Not a few banks use a credit as a means to attract customers or branding. The crediting process involves two parties, namely the bank as the creditor and the customer as the debtor. Lending or credit will increase the profit for the bank, but if it can't be managed properly will cause losses. Customers who are experiencing difficulties in paying installments to ultimately experience a default. This will result in bad debts for banks. If it is not handled seriously it will endanger the liquidity of the bank and end up in bankruptcy.
\end{abstract}

Keywords: Bad Debt, Qardh

(C) 2018 JBTI. All rights reserved

Article history : received 29 Des 2017; revised 9 Jan 2018; accepted 16 Jan 2018

\section{PENDAHULUAN}

Perekonomian Indonesia saat ini mulai menunjukkan perkembangan yang cukup signifikan. Perekonomian di Indonesia pada awalnya merupakan sistem perekonomian yang mengacu pada sistem konvensional yang menerapkan sistem bunga (interest) dalam memperoleh keuntungan, namun kini telah banyak lembaga keuangan seperti bank pembiayaan rakyat mulai membuka unit usaha dan merambah pada sistem berbasis syariah. Sistem syariah ini tidak mengandung unsur riba, gharar, maupun maisyir dan transaksi didalamnya sesuai dengan prinsip ekonomi Islam.

Berbagai lika-liku perkembangan lembaga keuangan, khususnya BPRS, tidak semua berjalan baik. Bahkan banyak ditemukan BPRS yang terpaksa tutup atau dinyatakan bangkrut. Banyak faktor yang menyebabkan bangkrutnya suatu lembaga keuangan, salah satunya adalah karena lembaga tersebut tidak mampu mengantisipasi adanya risiko kredit. Risiko kredit adalah risiko yang berkaitan dengan kemungkinan kegagalan debitur untuk melunasi utangnya (Kasidi, 2014). Suatu lembaga akan mengalami kerugian yang cukup besar jika debitur tidak mampu melunasi kewajibannya terhadap bank.

Hal tersebut menjelaskan bahwa tingginya tingkat piutang yang dikeluarkan oleh suatu lembaga keuangan. Jika tidak diikuti dengan pengelolaan manajemen risiko yang baik maka akan memberikan dampak negatif seperti bangkrutnya lembaga tersebut. Oleh karena itu diperlukan analisis secara mendalam sebelum pemberian kredit dan pembenahan dalam sistem manajerial sebagai salah satu upaya dalam mengantisipasi bangkrutnya suatu lembaga.

Salah satu BPRS terkemuka di Yogyakarta mengalami peningkatan aset yang cukup signifikan yakni BPRS Barokah Dana Sejahtera Yogyakarta. Pada tahun ke-9 beroperasinya (2016) Bank Syariah BDS (PT BPR Syariah Barokah Dana Sejahtera) terus menunjukkan trend yang 
positif, baik dari sisi aset, dana pihak ketiga, outstanding pembiayaan, modal dan laba. Edi Sunarto, Direktur Utama Bank Syariah BDS kepada Kedaulatan Rakyat, mengatakan, selama tahun 2016 Bank Syariah BDS mencatat aset sebesar Rp 78 miliar atau mengalami pertumbuhan 23,8\% dibanding tahun sebelumnya. Dana pihak ketiga Rp 64 miliar atau tumbuh 26,6\%, outstanding pembiayaan Rp 51 miliar atau tumbuh sebesar 18\% dan laba tahun 2016 sebesar Rp 1,4 miliar atau tumbuh sebesar 1,8\% (Tim BPRS BDS, 2017).

Salah satu produk pembiayaan yang terdapat pada BPRS Barokah Dana Sejahtera adalah qardh. Qardh adalah transaksi pinjam meminjam dana tanpa imbalan dengan kewajiban pihak peminjam mengembalikan pokok pinjaman secara sekaligus atau cicilan dalam jangka waktu tertentu (Muhammad, 2014). Pembiayaan qardh atau kredit melibatkan dua pihak yaitu pihak yang memberi kredit dan pihak yang menerima kredit, dimana akan timbul piutang bagi pihak kreditur dan hutang bagi pihak debitur.

Pembayaran secara berkala atau kredit pada suatu pembiayaan terkadang menimbulkan beberapa masalah seperti kredit yang tidak lancar bahkan kredit macet. Tidak semua nasabah bisa memenuhi kewajiban kepada pihak bank dengan lancar atau tepat waktu. Terkadang ada berbagai hambatan atau masalah yang ditemui nasabah sehingga dalam pelunasan kewajiban menjadi tersendat. Tidak bisa dihindari bahwa risiko pembiayaan dapat terjadi pada setiap jenis produk pembiayaan. Berbagai risiko usaha yang mungkin dihadapi nasabah adalah perekonomian yang sedang menurun, kebangkrutan bahkan menghilang, maka akan mengakibatkan munculnya piutang tak tertagih.

Adanya piutang bermasalah hingga piutang yang tidak tertagih tentu akan mengakibatkan kerugian bagi pihak bank. Dengan menggunakan metode penyisihan daftar umur piutang maka akan lebih mudah mengetahui posisi piutang tertentu. Dengan demikian bank bisa mengambil suatu kebijakan dan mengetahui dampak yang terjadi pada likuiditas bank. Dengan menggunakan daftar umur piutang maka akan lebih mudah mengetahui nasabah mana yang sudah jatuh tempo pembayaran dan dapat ditagih. Untuk tahun berikutnya bank tidak perlu khawatir mengenai kerugian piutang yang cukup besar, dikarenakan bank telah memiliki cadangan kerugian piutang yang dapat digunakan untuk menutup kerugian akibat piutang yang belum terbayar di periode tertentu. Sehingga bank tidak menderita kerugian yang besar akibat piutang yang tidak dapat ditagih.

Berdasarkan pemaparan pemikiran tersebut peneliti bermaksud membahas mengenai piutang qardh dengan menyusun penelitian yang berjudul "metode penyisihan piutang tak tertagih produk pada qardh di bank pembiayaan rakyat syariah (BPRS) Barokah Dana Sejahtera Yogyakarta periode 2017.

\section{KAJIAN TEORI}

\section{Daftar Umur Piutang}

Piutang merupakan dana yang disalurkan kepada nasabah dan wajib dibayarkan kembali kepada bank. Piutang timbul karena adanya pinjaman yang masa pelunasannya dilakukan secara berkala. Untuk mengantisipasi adanya kerugian yang dikhawatirkan tidak dapat dibayarkan oleh nasabah, maka diperlukan pencatatan secara terperinci. Salah satunya dengan membuat daftar umur piutang. Daftar umur piutang adalah skedul yang menggolongkan pelanggan berdasarkan jangka waktu belum bayar (Sugiri, 2001).

2. Skedul daftar umur piutang

Skedul daftar umur piutang merupakan perkiraan kerugian piutang yang sudah dikelompokkan dengan mencantumkan sebesar persentase tertentu. Adapun Peraturan Bank Indonesia untuk menganalisis piutang bermasalah dengan menggunakan metode daftar umur piutang dengan metode penyisihan ditentukan sebagai berikut (www.bi.go.id) : 
1) Penyisihan piutang secara umum ditetapkan paling sedikit sebesar $0,5 \%$ (nol koma lima persen) untuk kategori piutang lancar.

2) Penyisihan piutang secara khusus ditetapkan paling rendah sebesar:

a) $10 \%$ (sepuluh persen) dari Aktiva Produktif dan penempatan dana pada bank umum konvensional yang digolongkan Kurang Lancar setelah dikurangi nilai agunan

b) 50\% (lima puluh persen) dari Aktiva Produktif yang digolongkan Diragukan setelah dikurangi nilai agunan

c) $100 \%$ (seratus persen) dari Aktiva Produktif, Aktiva Non Produktif, dan penempatan dana pada bank umum konvensional yang digolongkan macet setelah dikurangi nilai agunan.

Tabel 1. Skedul Daftar Umur Piutang

\begin{tabular}{|c|c|c|}
\hline Kualitas Piutang & $\begin{array}{c}\text { Umur Piutang } \\
\text { (bulan) }\end{array}$ & Persentase Piutang \\
\hline Lancar & $1-3$ bulan & $0,5 \%$ \\
\hline Kurang Lancar & $3-6$ bulan & $10 \%$ \\
\hline Diragukan & $6-9$ bulan & $50 \%$ \\
\hline Macet & $9-12$ bulan & $100 \%$ \\
\hline
\end{tabular}

Sumber data: Peraturan Bank Indonesia, 2011

Tabel 2. Tabel Umur Piutang (Aging Schedule Of Accounts Receivable) Per 31 Desember 2016

\begin{tabular}{|l|l|l|l|l|l|l|}
\hline \multirow{2}{*}{ NO } & \multirow{2}{*}{$\begin{array}{c}\text { Nama } \\
\text { Nasabah }\end{array}$} & \multirow{2}{*}{$\begin{array}{c}\text { Jumlah } \\
\text { Piutang }\end{array}$} & \multicolumn{4}{|c|}{ Umur Piutang } \\
\cline { 3 - 6 } & & Rp. 00, & $\begin{array}{c}1-3 \\
\text { bulan }\end{array}$ & $\begin{array}{c}\text { 3-6 } \\
\text { bulan }\end{array}$ & $\begin{array}{c}\text { 6-12 } \\
\text { bulan }\end{array}$ & >1 tahun \\
\hline & & & & & \\
\hline Total & & & & & \\
\hline $\begin{array}{l}\text { Taksiran } \\
\text { Persentase Tak } \\
\text { Tertagih }\end{array}$ & & & & & & \\
\hline
\end{tabular}


3. Akuntansi Piutang Tak Tertagih

a. Metode Penghapusan Langsung

Metode Penghapusan Langsung (direct write-off method) adalah suatu cara dimana pencatatan kerugian yang timbul dari tidak tertagihnya piutang dilakukan pada saat piutang yang bersangkutan diputuskan untuk dihapuskan (Sumarno, 2002).

Tabel 3. Kerugian Piutang (Bad Debt)

\begin{tabular}{|l|l|l|l|l|l|}
\hline \multirow{2}{*}{ Tanggal } & Uraian & \multirow{2}{*}{ Debet } & \multirow{2}{*}{ Kredit } & \multicolumn{2}{|c|}{ Saldo } \\
\cline { 5 - 6 } & & & & Debet & Kredit \\
\hline 31 Des & Penyesuaian & $\mathrm{xxx}$ & & $\mathrm{xxx}$ & \\
\hline
\end{tabular}

Tabel 4. Piutang Usaha (Account Receivable)

\begin{tabular}{|l|l|l|l|l|l|}
\hline \multirow{2}{*}{ Tanggal } & Uraian & \multirow{2}{*}{ Debet } & \multirow{2}{*}{ Kredit } & \multicolumn{2}{|c|}{ Saldo } \\
\cline { 4 - 6 } & & & & Debet & Kredit \\
\hline 31 Des & Penyesuaian & & $\mathrm{xxx}$ & & $\mathrm{xxx}$ \\
\hline
\end{tabular}

b. Metode Penyisihan atau Metode Tidak Langsung

Metode Penyisihan atau Metode Tidak Langsung (allowance for doubtfull account) adalah bagian dari piutang yang diperkirakan tidak akan dapat ditagih dan untuk kemungkinan kerugian yang disebabkan olehnya telah dicatat sebagai beban (Sumarso, 2002).

Tabel 5. Kerugian Piutang (Bad Debt)

\begin{tabular}{|l|l|l|l|l|l|}
\hline \multirow{2}{*}{ Tanggal } & Uraian & \multirow{2}{*}{ Debet } & \multirow{2}{*}{ Kredit } & \multicolumn{2}{|c|}{ Saldo } \\
\cline { 5 - 6 } & & & & Debet & Kredit \\
\hline 31 Des & Penyesuaian & $\mathrm{xxx}$ & & $\mathrm{xxx}$ & \\
\hline
\end{tabular}

Tabel 6. Cadangan Kerugian Piutang (CKP) (Allowance For Bad Debt)

\begin{tabular}{|l|l|l|l|l|l|}
\hline \multirow{2}{*}{ Tanggal } & \multirow{2}{*}{ Uraian } & \multirow{2}{*}{ Debet } & \multirow{2}{*}{ Kredit } & \multicolumn{2}{|c|}{ Saldo } \\
\cline { 5 - 6 } & & & & Debet & \multicolumn{1}{|c|}{ Kredit } \\
\hline 31 Des & Penyesuaian & & $\mathrm{xxx}$ & & $\mathrm{xxx}$ \\
\hline & & & $\mathrm{xxx}$ & & $\mathrm{xxx}$ \\
\hline
\end{tabular}


Tabel 7. Neraca (Balance Sheet)

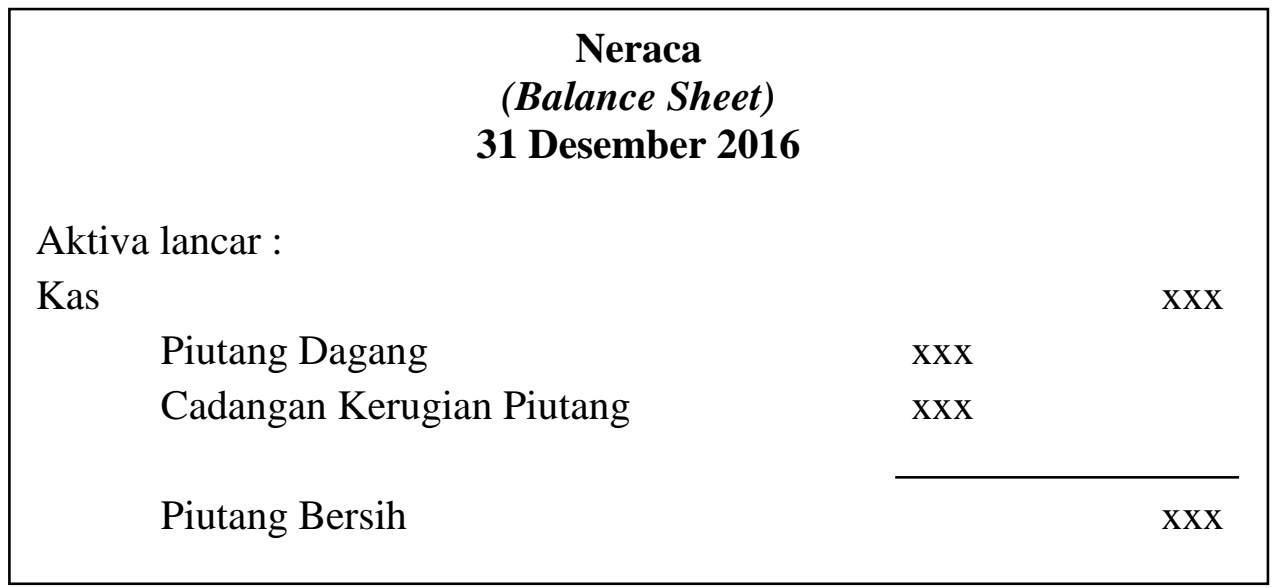

\section{Qardh}

Salah satu produk pembiayaan yang ditawarkan BPRS adalah qardh. Qardh diartikan sebagai mekanisme pinjam meminjam dana tanpa imbalan dengan kewajiban pihak peminjam mengembalikan pokok pinjaman secara sekaligus atau cicilan dalam jangka waktu tertentu (Muhammad, 2014). Dalam pembiayaan qardh tidak terdapat bagi hasil seperti pembiayaan pada umumnya. Qardh hanya dikenakan biaya adminitrasi diawal dan pengembaliannya sebesar pokok pinjaman.

a. Landasan Hukum Syariah Produk Qardh

Landasan hukum syariah pada produk qardh terdapat pada Al Quran Surat Al Baqarah ayat 245 (QS Al Baqarah 2:245) :

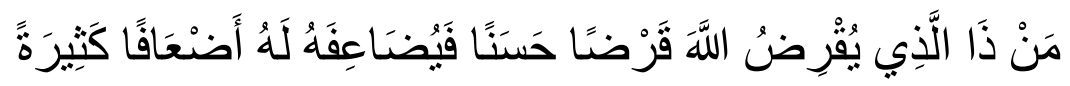

Artinya:

"Siapakah yang mau memberi pinjaman kepada Allah, pinjaman yang baik (menafkahkan hartanya di jalan Allah), Maka Allah akan meperlipat gandakan pembayaran kepadanya dengan lipat ganda yang banyak". (QS. al-Baqarah: 245)

Ayat tersebut menjelaskan bahwa pemberian pinjaman kepada orang lain terlebih pinjaman yang digunakan untuk kegiatan keagamaan merupakan pemberian pinjaman yang tergolong baik karena akan meringankan beban orang lain dalam himpitan ekonomi. Dalam praktik perbankan syariah, pemberian pinjaman yang baik yakni dapat berupa pembiayaan qardh. Karena pada pembiayaan qardh, nasabah hanya mengembalikan sebesar pinjaman pokok tanpa adanya bunga yang akan memberatkan nasabah.

\section{METODE PENELITIAN}

A. Jenis data

1. Data Primer

Data primer diperoleh dari narasumber pertama yang teknik pengumpulan datanya menggunakan metode wawancara yang meliputi pihak terkait seperti manager oprasional, manajer marketing, dan accounting. 


\section{Data sekunder}

Data sekunder diperoleh dari data pendukung seperti buku bacaan, dokumen, brosur, atau tulisan yang berkaitan dengan tema penelitia (Tjahjono, 2015).

\section{B. Metode Penelitian}

Metode yang digunakan dalam penelitian ini adalah dengan metode penelitian deskriptif kualitatif. Peneliti menggunakan metode ini untuk meneliti dan menemukan secara rinci dan lebih mendalam tentang metode penyisihan piutang tak tertagih produk qardh di BPRS Barokah Dana Sejahtera Yogyakarta.

C. Teknik Analisis Data

Analisis data yang dilakukan meliputi data reduction, data display, dan cuncluusion drawing/verification (Sugiyono, 2014). Menurut Bogdan dan Biklen, analisis data kualitatif adalah upaya yang dilakukan dengan jalan bekerja dengan data, mengorganisasikan data, memilah-milahnya menjadi satuan yang dapat dikelola, mensintesiskannya, mencari dan menemukan pola, menemukan apa yang penting dan apa yang dipelajari, serta memutuskan apa yang dapat diceritakan kepada oranglain (Moloeng, 1989).

\section{HASIL DAN PEMBAHASAN}

1. Gambaran Umum BPRS Barokah Dana Sejahtera Yogyakarta

Proses pendirian Bank Pembiayaan Rakyat Syariah (Barokah Dana Sejahtera) Yogyakarta dimulai pada bulan Agustus 2005. Pada tanggal 6 Desember 2006 keluar izin prinsip pendirian dari Bank Indonesia dengan nomor : 8/251/DPbs, baru kemudian tanggal 6 Juli 2007 disahkan akta pendirian PT dari Menteri Hukum dan HAM dengan nomor W22-00107 HT.01.01-th 2007. Selanjutnya pada tanggal 29 Juli 2007 adalah proses penyampaian surat permohonan izin usaha kepada Bank Indonesia dengan nama Bank Pembiayaan Rakyat Syariah (Barokah Dana Sejahtera), pemegang saham ditetapkan berjumlah delapan orang (Tim BPRS BDS, 2018).

Pada tahun ke-9 beroperasinya (2016) Bank Syariah BDS (PT BPR Syariah Barokah Dana Sejahtera) terus menunjukkan trend yang positif, baik dari sisi aset, dana pihak ketiga, outstanding pembiayaan, modal dan laba. Edi Sunarto, Direktur Utama Bank Syariah BDS kepada Kedaulatan Rakyat, mengatakan, selama tahun 2016 Bank Syariah BDS mencatat aset sebesar Rp 78 miliar atau mengalami pertumbuhan 23,8\% dibanding tahun sebelumnya. Dana pihak ketiga Rp 64 miliar atau tumbuh 26,6\%, outstanding pembiayaan Rp 51 miliar atau tumbuh sebesar 18\% dan laba tahun 2016 sebesar Rp 1,4 miliar atau tumbuh sebesar 1,8\% (Tim BPRS BDS, 2017).

\section{Analisis Daftar Umur Piutang Qardh}

Daftar umur piutang merupakan metode yang digunakan dalam mengklasifikasikan piutang menurut kolektibilitasnya yang tertuang dalam bentuk laporan keuangan. Dalam daftar umur piutang terdapat beberapa keterangan seperti nama nasabah, jangka waktu pelunasan hutang, tanggal jatuh tempo, jumlah piutang, dan kolektibilatas piutang atau kategori kelancaran pembayaran angsuran oleh nasabah. Daftar umur piutang dibuat pada setiap akhir tahun 
Tabel 8. Daftar Umur Piutang (Aging Schedule Of Account Receivable) Dalam satuan ribuan Per 31 Desember 2017

\begin{tabular}{|c|c|c|c|c|c|c|c|c|}
\hline \multirow{2}{*}{ No } & \multirow{2}{*}{ Nama Nasabah } & \multirow{2}{*}{$\begin{array}{l}\text { Jangka } \\
\text { Waktu }\end{array}$} & \multirow{2}{*}{$\begin{array}{c}\text { Tanggal Jatuh } \\
\text { Tempo }\end{array}$} & \multirow{2}{*}{$\begin{array}{l}\text { Jumlah } \\
\text { Piutang }\end{array}$} & \multirow{2}{*}{$\begin{array}{c}\begin{array}{c}\text { Belum Jatuh } \\
\text { Tempo }\end{array} \\
\text { 1-3 bulan } \\
\text { (Lancar) }\end{array}$} & \multicolumn{3}{|c|}{ Menunggak } \\
\hline & & & & & & $\begin{array}{c}\text { 3-6 bulan } \\
\text { (Kurang } \\
\text { lancar) }\end{array}$ & $\begin{array}{l}\text { 6-12 bulan } \\
\text { (Diragukan) }\end{array}$ & $\begin{array}{c}>1 \text { tahun } \\
\text { (Macet) }\end{array}$ \\
\hline 1 & Yuni & 60 & $29 / 12 / 2017$ & 76,00 & 76,00 & & & \\
\hline 2 & Sri & 60 & $25 / 02 / 2018$ & $16.900,00$ & $16.900,00$ & & & \\
\hline 3 & Lilis & 60 & $25 / 02 / 2018$ & $16.900,00$ & $16.900,00$ & & & \\
\hline 4 & Ahmad & 60 & $13 / 03 / 2018$ & $31.007,00$ & & & & $31.007,00$ \\
\hline 5 & Hasan & 24 & $25 / 12 / 2017$ & $2.000,00$ & & & & $2.000,00$ \\
\hline 6 & Arif $\mathrm{S}$. & 24 & $25 / 01 / 2018$ & $20.000,00$ & $20.000,00$ & & & \\
\hline 7 & Hasnan & 24 & $16 / 03 / 2018$ & $2.000,00$ & $2.000,00$ & & & \\
\hline 8 & Ruli & 24 & $15 / 08 / 2018$ & $23.400,00$ & $23.400,00$ & & & \\
\hline 9 & Indah & 24 & $18 / 09 / 2018$ & $18.000,00$ & $18.000,00$ & & & \\
\hline 10 & Suci & 12 & $17 / 10 / 2017$ & $17.700,00$ & & & $17.700,00$ & \\
\hline 11 & Retno & 12 & $17 / 10 / 2017$ & $17.700,00$ & & & $17.700,00$ & \\
\hline 12 & Nur & 24 & $21 / 08 / 2018$ & 450,00 & 450,00 & & & \\
\hline
\end{tabular}




\begin{tabular}{|c|c|c|c|c|c|c|c|c|}
\hline \multirow{2}{*}{ No } & \multirow{2}{*}{ Nama Nasabah } & \multirow{2}{*}{$\begin{array}{l}\text { Jangka } \\
\text { Waktu }\end{array}$} & \multirow{2}{*}{$\begin{array}{c}\text { Tanggal Jatuh } \\
\text { Tempo }\end{array}$} & \multirow{2}{*}{$\begin{array}{l}\text { Jumlah } \\
\text { Piutang }\end{array}$} & \multirow{2}{*}{$\begin{array}{c}\begin{array}{c}\text { Belum Jatuh } \\
\text { Tempo }\end{array} \\
\text { 1-3 bulan } \\
\text { (Lancar) }\end{array}$} & \multicolumn{3}{|c|}{ Menunggak } \\
\hline & & & & & & $\begin{array}{c}\text { 3-6 bulan } \\
\text { (Kurang } \\
\text { lancar) }\end{array}$ & $\begin{array}{l}\text { 6-12 bulan } \\
\text { (Diragukan) }\end{array}$ & $\begin{array}{c}>\text { 1 tahun } \\
\text { (Macet) }\end{array}$ \\
\hline 13 & Bambang & 12 & $13 / 01 / 2018$ & 167,00 & 167,00 & & & \\
\hline 14 & Siti & 12 & $23 / 02 / 2018$ & $23.400,00$ & $23.400,00$ & & & \\
\hline 15 & Puri & 12 & $23 / 02 / 2018$ & $23.400,00$ & $23.400,00$ & & & \\
\hline 16 & Endang & 12 & $23 / 02 / 2018$ & $23.400,00$ & $23.400,00$ & & & \\
\hline 17 & Husen & 12 & $23 / 02 / 2018$ & $23.400,00$ & $23.400,00$ & & & \\
\hline 18 & Antok & 12 & $23 / 02 / 2018$ & $23.400,00$ & $23.400,00$ & & & \\
\hline 19 & Fatah & 12 & $23 / 02 / 2018$ & $23.400,00$ & $23.400,00$ & & & \\
\hline 20 & Samsul & 12 & $23 / 02 / 2018$ & $23.400,00$ & $23.400,00$ & & & \\
\hline 21 & Udin & 12 & $23 / 02 / 2018$ & $23.400,00$ & $23.400,00$ & & & \\
\hline 22 & Bagus & 12 & $25 / 03 / 2018$ & $7.350,00$ & $7.350,00$ & & & \\
\hline 23 & Hadi & 12 & $18 / 04 / 2018$ & $23.400,00$ & $23.400,00$ & & & \\
\hline 24 & Taufik & 12 & $18 / 04 / 2018$ & $23.400,00$ & $23.400,00$ & & & \\
\hline 25 & Sri K. & 12 & 07/06/2018 & 500,00 & 500,00 & & & \\
\hline 26 & Desi P. & 12 & $20 / 06 / 2018$ & 583,00 & 583,00 & & & \\
\hline
\end{tabular}




\begin{tabular}{|c|c|c|c|c|c|c|c|c|}
\hline \multirow{2}{*}{ No } & \multirow{2}{*}{ Nama Nasabah } & \multirow{2}{*}{$\begin{array}{l}\text { Jangka } \\
\text { Waktu }\end{array}$} & \multirow{2}{*}{$\begin{array}{c}\text { Tanggal Jatuh } \\
\text { Tempo }\end{array}$} & \multirow{2}{*}{$\begin{array}{l}\text { Jumlah } \\
\text { Piutang }\end{array}$} & \multirow{2}{*}{$\begin{array}{c}\begin{array}{c}\text { Belum Jatuh } \\
\text { Tempo }\end{array} \\
\text { 1-3 bulan } \\
\text { (Lancar) }\end{array}$} & \multicolumn{3}{|c|}{ Menunggak } \\
\hline & & & & & & $\begin{array}{c}\text { 3-6 bulan } \\
\text { (Kurang } \\
\text { lancar) }\end{array}$ & $\begin{array}{c}\text { 6-12 bulan } \\
\text { (Diragukan) }\end{array}$ & $\begin{array}{c}>1 \text { tahun } \\
\text { (Macet) }\end{array}$ \\
\hline 27 & Dian & 12 & $20 / 06 / 2018$ & 583,00 & 583,00 & & & \\
\hline 28 & Ikhsan & 12 & $10 / 08 / 2018$ & $1.875,00$ & $1.875,00$ & & & \\
\hline 29 & Zuhri & 12 & $16 / 08 / 2018$ & $2.025,00$ & $2.025,00$ & & & \\
\hline 30 & Hanan & 12 & $21 / 08 / 2018$ & $1.875,00$ & $1.875,00$ & & & \\
\hline 31 & Fitri & 12 & $21 / 08 / 2018$ & $2.025,00$ & $2.025,00$ & & & \\
\hline 32 & Yuni & 12 & $21 / 01 / 2018$ & 800,00 & 800,00 & & & \\
\hline 33 & Husni & 12 & $23 / 08 / 2018$ & $2.025,00$ & $2.025,00$ & & & \\
\hline 34 & Ramdani & 12 & $23 / 08 / 2018$ & $2.025,00$ & $2.025,00$ & & & \\
\hline 35 & Maher & 12 & $23 / 08 / 2018$ & $2.025,00$ & $2.025,00$ & & & \\
\hline 36 & Ghani & 12 & $26 / 08 / 2018$ & $2.025,00$ & $2.025,00$ & & & \\
\hline 37 & Aryo W. & 12 & $26 / 08 / 2018$ & $2.025,00$ & $2.025,00$ & & & \\
\hline 38 & Dwiki & 12 & $26 / 08 / 2018$ & $2.025,00$ & $2.025,00$ & & & \\
\hline 39 & Rohmat & 12 & $28 / 08 / 2018$ & $1.875,00$ & $1.875,00$ & & & \\
\hline
\end{tabular}




\begin{tabular}{|c|c|c|c|c|c|c|c|c|}
\hline \multirow{2}{*}{ No } & \multirow{2}{*}{ Nama Nasabah } & \multirow{2}{*}{$\begin{array}{l}\text { Jangka } \\
\text { Waktu }\end{array}$} & \multirow{2}{*}{$\begin{array}{c}\text { Tanggal Jatuh } \\
\text { Tempo }\end{array}$} & \multirow{2}{*}{$\begin{array}{l}\text { Jumlah } \\
\text { Piutang }\end{array}$} & \multirow{2}{*}{$\begin{array}{c}\begin{array}{c}\text { Belum Jatuh } \\
\text { Tempo }\end{array} \\
\text { 1-3 bulan } \\
\text { (Lancar) }\end{array}$} & \multicolumn{3}{|c|}{ Menunggak } \\
\hline & & & & & & $\begin{array}{c}\text { 3-6 bulan } \\
\text { (Kurang } \\
\text { lancar) }\end{array}$ & $\begin{array}{c}\text { 6-12 bulan } \\
\text { (Diragukan) }\end{array}$ & $\begin{array}{c}>1 \text { tahun } \\
\text { (Macet) }\end{array}$ \\
\hline 40 & Asep & 12 & $28 / 08 / 2018$ & $2.025,00$ & $2.025,00$ & & & \\
\hline 41 & Jauhari & 12 & $29 / 08 / 2018$ & $2.025,00$ & $2.025,00$ & & & \\
\hline 42 & Lukman & 12 & $28 / 08 / 2018$ & $2.025,00$ & $2.025,00$ & & & \\
\hline 43 & Ilyas & 12 & $30 / 08 / 2018$ & $2.475,00$ & $2.475,00$ & & & \\
\hline 44 & Septi & 12 & $20 / 10 / 2018$ & $23.400,00$ & $23.400,00$ & & & \\
\hline 45 & Mukti & 12 & $20 / 10 / 2018$ & $23.400,00$ & $23.400,00$ & & & \\
\hline 46 & Zahrotunisa & 12 & $23 / 10 / 2018$ & $23.400,00$ & $23.400,00$ & & & \\
\hline 47 & Shafa & 12 & $23 / 10 / 2018$ & $23.400,00$ & $23.400,00$ & & & \\
\hline 48 & Endar & 12 & $25 / 10 / 2018$ & $23.400,00$ & $23.400,00$ & & & \\
\hline 49 & Suraji & 12 & $25 / 10 / 2018$ & $23.400,00$ & $23.400,00$ & & & \\
\hline 50 & Ratman & 12 & 08/11/2018 & $3.000,00$ & $3.000,00$ & & & \\
\hline 51 & Asih & 12 & $22 / 11 / 2018$ & $17.750,00$ & $17.750,00$ & & & \\
\hline 52 & Hanung & 12 & $22 / 11 / 2018$ & $17.750,00$ & $17.750,00$ & & & \\
\hline 53 & Yoga P. & 48 & 27/06/2019 & $4.079,00$ & $4.079,00$ & & & \\
\hline
\end{tabular}




\begin{tabular}{|c|c|c|c|c|c|c|c|c|}
\hline \multirow{2}{*}{ No } & \multirow{2}{*}{ Nama Nasabah } & \multirow{2}{*}{$\begin{array}{l}\text { Jangka } \\
\text { Waktu }\end{array}$} & \multirow{2}{*}{$\begin{array}{c}\text { Tanggal Jatuh } \\
\text { Tempo }\end{array}$} & \multirow{2}{*}{$\begin{array}{l}\text { Jumlah } \\
\text { Piutang }\end{array}$} & \multirow{2}{*}{$\begin{array}{c}\begin{array}{c}\text { Belum Jatuh } \\
\text { Tempo }\end{array} \\
\text { 1-3 bulan } \\
\text { (Lancar) }\end{array}$} & \multicolumn{3}{|c|}{ Menunggak } \\
\hline & & & & & & $\begin{array}{c}\text { 3-6 bulan } \\
\text { (Kurang } \\
\text { lancar) }\end{array}$ & $\begin{array}{c}\text { 6-12 bulan } \\
\text { (Diragukan) }\end{array}$ & $\begin{array}{c}>1 \text { tahun } \\
\text { (Macet) }\end{array}$ \\
\hline 54 & Muji & 24 & $19 / 07 / 2018$ & $23.400,00$ & $23.400,00$ & & & \\
\hline 55 & Lina & 24 & $19 / 07 / 2018$ & $23.400,00$ & $23.400,00$ & & & \\
\hline 56 & Sarjiyem & 12 & 08/03/2018 & $23.400,00$ & $23.400,00$ & & & \\
\hline 57 & Wanti & 12 & 08/03/2018 & $23.400,00$ & $23.400,00$ & & & \\
\hline 58 & Subkhan & 12 & $16 / 06 / 2018$ & $18.400,00$ & $18.400,00$ & & & \\
\hline 59 & Fakhrul & 12 & $16 / 06 / 2018$ & $18.400,00$ & $18.400,00$ & & & \\
\hline 60 & Syamsir L. & 12 & $16 / 06 / 2018$ & $18.400,00$ & $18.400,00$ & & & \\
\hline 61 & Huda & 12 & $16 / 06 / 2018$ & $18.400,00$ & $18.400,00$ & & & \\
\hline 62 & Parjiyah & 12 & $07 / 07 / 2018$ & $23.400,00$ & $23.400,00$ & & & \\
\hline 63 & Arifin & 12 & $07 / 07 / 2018$ & $23.400,00$ & $23.400,00$ & & & \\
\hline 64 & Fadli S. & 12 & $14 / 07 / 2018$ & $23.400,00$ & $23.400,00$ & & & \\
\hline 65 & Watini & 48 & $28 / 07 / 2021$ & $23.000,00$ & $23.000,00$ & & & \\
\hline 66 & Purwanti & 12 & $24 / 08 / 2018$ & $2.025,00$ & $2.025,00$ & & & \\
\hline
\end{tabular}




\begin{tabular}{|c|c|c|c|c|c|c|c|c|}
\hline \multirow{2}{*}{ No } & \multirow{2}{*}{ Nama Nasabah } & \multirow{2}{*}{$\begin{array}{l}\text { Jangka } \\
\text { Waktu }\end{array}$} & \multirow{2}{*}{$\begin{array}{c}\text { Tanggal Jatuh } \\
\text { Tempo }\end{array}$} & \multirow{2}{*}{$\begin{array}{l}\text { Jumlah } \\
\text { Piutang }\end{array}$} & \multirow{2}{*}{$\begin{array}{c}\begin{array}{c}\text { Belum Jatuh } \\
\text { Tempo }\end{array} \\
\text { 1-3 bulan } \\
\text { (Lancar) }\end{array}$} & \multicolumn{3}{|c|}{ Menunggak } \\
\hline & & & & & & $\begin{array}{c}\text { 3-6 bulan } \\
\text { (Kurang } \\
\text { lancar) }\end{array}$ & $\begin{array}{c}\text { 6-12 bulan } \\
\text { (Diragukan) }\end{array}$ & $\begin{array}{l}>1 \text { tahun } \\
\text { (Macet) }\end{array}$ \\
\hline 67 & Mukhlis & 12 & $28 / 02 / 2018$ & $1.250,00$ & $1.250,00$ & & & \\
\hline 68 & Ujang & 12 & $29 / 08 / 2018$ & $23.400,00$ & $23.400,00$ & & & \\
\hline 69 & Ratman & 12 & $29 / 08 / 2018$ & $23.400,00$ & $23.400,00$ & & & \\
\hline \multicolumn{4}{|c|}{ TOTAL } & 933.945,00 & $865.538,00$ & - & $35.400,00$ & $33.007,00$ \\
\hline \multicolumn{4}{|c|}{ Taksiran Persentase Tak Tertagih } & & $0.5 \%$ & $10 \%$ & $50 \%$ & $100 \%$ \\
\hline \multicolumn{4}{|c|}{ Total Taksiran Tak Tertagih } & 55.034 .690 & 4.327.690 & - & 17.700 .000 & 33.007.000 \\
\hline
\end{tabular}

Sumber: Data primer diolah tahun 2017. 
Berdasarkan tabel daftar umur piutang tersebut diketahui total kerugian piutang produk qardh BPRS Barokah Dana Sejahtera tahun 2017 sebesar Rp.55.034.690,00 (Lima Puluh Lima Juta Tiga Puluh Empat Ribu Enam Ratus Sembilan Puluh Rupiah). Saldo cadangan kerugian piutang berada pada saldo kredit sebesar Rp.7.345.000,00 (Tujuh Juta Tiga Ratus Empat Puluh Lima Ribu Rupiah). Rumus yang digunakan adalah (Magpantay, 2014) :

$$
A B D b e g+B D c y=A B D e n d
$$

Arti dari rumus tersebut adalah ABDbeg merupakan Allowance for Bad Debts, Beginning Balance atau saldo yang ada pada rekening cadangan kerugian piutang sebelum penyesuaian. ABDend adalah Allowance for Bad Debts Ending Balance atau yang disebut dengan cadangan kerugian piutang. BDcy adalah Bad Debt Expense, Current Year atau biasa disebut dengan kerugian piutang yaang dialami pada periode tertentu. Berdasarkan rumus tersebut maka perhitungannya adalah sebagai berikut:

ABDbeg + BDcy= ABDend
Rp.7.345.000,00 + BDcy $=$ Rp.55.034.690,00
$B D c y=$ Rp.55.034.690,00 - Rp.7.345.000,00
BDcy $=$ Rp.47.689.690

Tabel 9. Kerugian Piutang (Bad Debt)

\begin{tabular}{|l|c|c|c|c|c|}
\hline \multirow{2}{*}{ Tanggal } & \multirow{2}{*}{ Uraian } & Debet & \multirow{2}{*}{ Kredit } & \multicolumn{2}{|c|}{ Saldo } \\
\cline { 5 - 7 } & & & & Debet & Kredit \\
\hline 31 Des & Penyesuaian & 47.689 .690 & & 47.689 .690 & \\
\hline
\end{tabular}

Kerugian piutang (bad debt) merupakan kerugian yang dialami oleh perusahaan pada periode tertentu. Berdasarkan tabel kerugian piutang BPRS BDS pada tahun 2017 mengalami kerugian piutang sebesar Rp.47.689.690,00 (Empat Puluh Tujuh Juta Enam Ratus Delapan Puluh Sembilan Ribu Enam Ratus Sembilan Puluh Rupiah).

Tabel 10. Cadangan Kerugian Piutang (CKP) (Allowance For Bad Debt)

No.114

\begin{tabular}{|l|l|l|l|l|l|}
\hline \multirow{2}{*}{ Tanggal } & \multirow{2}{*}{ Uraian } & \multirow{2}{*}{ Debet } & \multirow{2}{*}{ Kredit } & \multicolumn{2}{|c|}{ Saldo } \\
\cline { 5 - 6 } & & & & Debet & Kredit \\
\hline 31 Des & Saldo & & 7.345 .000 & & 7.345 .000 \\
\hline & Penyesuaian & & 47.689 .690 & & 55.034 .690 \\
\hline
\end{tabular}

Cadangan kerugian piutang merupakan cadangan kerugian yang dibentuk oleh perusahaan untuk menganggulangi adanya piutang tak tertagih atau kredit macet. Cadangan kerugian piutang yang dibentuk berdasarakan daftar umur piutang produk qardh tahun 2017 sebesar Rp.55.034.690,00 
(Lima Puluh Lima Juta Tiga Puluh Empat Ribu Enam Ratus Sembilan Puluh Rupiah). Di dalam neraca, cadangan kerugian kerugian piutang akan mengurangi piutang yang dimiliki oleh BPRS BDS. Untuk memperoleh jumlah piutang bersih maka rumusnya adalah:

Piutang - Cadangan Kerugian Piutang = Piutang Bersih

Tabel 11. Neraca (Balance Sheet)

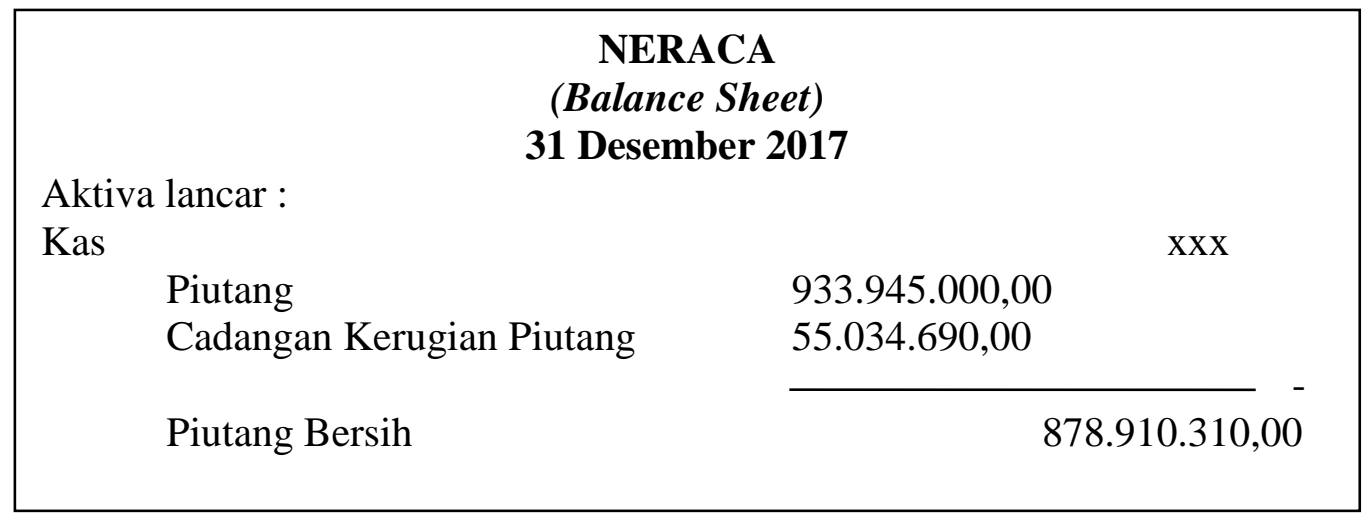

Neraca merupakan salah satu laporan keuangan yang menunjukkan posisi aktiva dan pasiva yang dimiliki oleh perusahaan di masa sekarang. Aktiva mencerminkan harta yang dimiliki suatu perusahaan sedangkan pasiva adalah sumber dari harta tersebut. Aktiva terdiri dari aktiva lancar dan aktiva tetap. Aktiva lancar merupakan harta yang mudah untuk dicairkan atau diuangkan dan cenderung cepat terjadi perubahan. Kewajiban terdiri dari hutang jangka pendek dan hutang jangka panjang (Kasmir, 2010).

\section{KESIMPULAN}

\section{A. Kesimpulan}

BPRS Barokah Dana Sejahtera Yogyakarta menggunakan metode tidak langsung (allowance for doubtfull account) dalam penyisihan piutang tak tertagih pada produk qardh. Metode tidak langsung atau disebut dengan metode penyisihan yakni dengan membentuk cadangan kerugian piutang berdasarkan kualitas dan saldo piutang dengan menetapkan persentase tertentu sesuai dengan ketentuan yang ditetapkan oleh Peraturan Bank Indonesia.

Hasil analisis piutang tak tertagih pada produk qardh dengan menggunakan metode penyisihan daftar umur piutang dapat diketahui jumlah kerugian piutang (bad debt) pada tahun 2017 sebesar Rp.47.689.690,00 (Empat Puluh Tujuh Juta Enam Ratus Delapan Puluh Sembilan Ribu Enam Ratus Sembilan Puluh Rupiah). Jumlah cadangan kerugian piutang (allowance for bad debt) sebesar Rp.55.034.690,00 (Lima Puluh Lima Juta Tiga Puluh Empat Ribu Enam Ratus Sembilan Puluh Rupiah). Cadangan kerugian piutang akan digunakan untuk menutup kerugian yang akan terjadi pada periode yang akan datang. Untuk jumlah piutang bersih diperoleh hasil sebesar Rp.878.910.310,00 (Delapan Ratus Tujuh Puluh Delapan Juta Sembilan Ratus Sepuluh Ribu Tiga Ratus Sepuluh Rupiah). 


\section{SARAN}

1. Mengingat piutang bersih produk qardh BPRS BDS masih menunjukkan jumlah yang cukup tinggi, diharapkan pihak BPRS BDS secara intens memberikan penyuluhan kepada nasabah agar tidak terlambat dalam membayar angsuran sehingga dapat meminimalisir adanya piutang tak tertagih.

2. Memberikan reward kepada nasabah yang membayar angsuran secara rutin dan tepat waktu. Hal ini dapat memotivasi nasabah agar tidak terlambat membayar angsuran.

3. Produk qardh dapat dijadikan sebagai favorite product karena tujuan adanya qardh adalah untuk kemaslahatan umat.

\section{DAFTAR PUSTAKA}

Al Quran Surat Al Baqarah (2): 245

Kasidi, (2014), Manajemen Risiko, Bogor : Ghalia Indonesia.

Kasmir, (2010), Analisis Laporan Keuangan, Jakarta : Raja Grafindo.

Magpantay, D., (2013), Equivalence of the 3 Methods of Estimating Bad Debts", International Journal of Science and Research, Jurnal, Volume 2 Issue 1.

Moleong, Lexy J., (1989), Metodologi Penelitian Kualitatif, Bandung : PT Remaja Rosdakarya.

Muhammad, (2014), Manajemen Dana Bank Syariah, Jakarta : Rajawali Pers.

Peraturan Bank Indonesia Nomor 13/14/PBI 2011 Tentang Penilaian Kualitas Aktiva Bagi Bank Pembiayaan Rakyat Syariah, Pasal 19, http://www.bi.go.id, diakses pada tanggal 4 Januari 2018, pukul 20.35 WIB.

Sugiri, S., (2001), Akuntansi Pengantar, Yogyakarta:UPP AMP YKPN.

Sugiyono, (2014), Metode Penelitian Kuantitatif, Kualitatif, dan R\&D, Bandung : Alfabeta.

Sumarso, (2002), Akuntansi Suatu Pengantar, Jakarta : Salemba Empat.

Tim BPRS BDS, Awal Mula Bank Syariah BDS ,http://www.bprs-bds.co.id/sejarah ,diakses 16 April 2018 pkl 20:44

Tim BPRS BDS, Awal Mula Bank Syariah BDS ,http://www.bprs-bds.co.id/sejarah ,diakses 16 April 2017 pkl 20:44.

Tjahjono, H.K. (2015). Metode Penelitian Bisnis. VSM MM UMY

Daningrum, J dan Mikhriani | Metode Penyisihan Piutang Tak Tertagih Pada Produk Qardh di Bank Pembiayaaan... 